\title{
Pattern of movements within a home reef in the Chesterfield Islands (Coral Sea) by the endangered Giant Grouper, Epinephelus lanceolatus ${ }^{\star}$
}

\author{
Eric CluA $^{1, a}$, Claude CHAUvet ${ }^{2}$, Johann MourIER ${ }^{1}$, Jonathan Mark WerRY ${ }^{3,4,5}$ and John E. RANDALL ${ }^{6}$ \\ 1 LabEx "CORAIL" - USR 3278 CNRS-EPHE, Centre de Recherche Insulaire et Observatoire de l'Environnement (CRIOBE), \\ BP 1013, 98729 Papetoai, Moorea, French Polynesia \\ 2 University of New Caledonia, BP 12814, 98802 Noumea, New Caledonia \\ 3 Australian Rivers Institute and School of Environment, Griffith University, Gold Coast campus, Parklands Drive, Southport, \\ Queensland 4222, Australia \\ ${ }^{4}$ Griffith Centre for Coastal Management, Griffith University, Gold Coast campus, Parklands Drive, Southport, Queensland 4222, Australia \\ 5 Ocean and Coast Research, Gold Coast, Queensland 4217, Australia \\ ${ }^{6}$ Bishop Museum, 1525 Bernice St., Honolulu, HI 96817-2704, USA
}

Received 20 May 2015; Accepted 27 August 2015

\begin{abstract}
This study determined the movements of a Giant Grouper, Epinephelus lanceolatus, in which an acoustic tag was surgically implanted and monitored by an array of six VR2W acoustic receiver units from August 2010 to January 2013 in the remote, uninhabited Chesterfield Islands, Coral Sea (800 km West of New Caledonia). Our data revealed a home reef area (residency rate of $44.9 \%$ ) with an increased activity revealed by movements at dawn and dusk toward and between two adjacent reef passages, probably for foraging. The fish was absent from its resident reef between October and December 2010 and 2012, corresponding to the time known for spawning aggregations of this species in New Caledonia. A skipped spawning seems to have occurred in 2011. We hope these data will be complemented in the future by locating the spawning site or sites and thus provide adequate conservation measures. The Coral Sea links two World Heritage Sites, the Australian Great Barrier Reefs and the New Caledonian coral reefs. It would be fitting to create a Marine Protected Area for the Chesterfield Islands between these two major conservation areas of the sea.
\end{abstract}

Keywords: Coral reefs apex predator / serranidae / site fidelity / acoustic telemetry / spawning aggregations

\section{Introduction}

With a maximum total length (TL) of $2.3 \mathrm{~m}$ and weight of $300 \mathrm{~kg}$, the Indo-Pacific Giant Grouper, Epinephelus lanceolatus (Bloch 1790) is the largest known reef fish. It is usually found on coral reefs, especially where there are large caves, but it is also known from harbours and deep estuaries, as well as on wrecks and man-made structures, such as those for oil exploration or wind generators. Although reported to a depth of $100 \mathrm{~m}$, it is usually found in much shallower water. It preys mainly on spiny lobsters, small elasmobranchs, a variety of bony fishes, large crabs, octopuses, and juvenile marine turtles (Witzell 1981; Heemstra and Randall 1993). It is the most widely distributed grouper in the world, from South Africa and the Red Sea to the Pitcairn Islands (Randall and Heemstra 1991; Randall 1995).

\footnotetext{
* Supporting information is only available in electronic form at www.alr-journal.org.

a Corresponding author: eric.clua@gmail.com
}

Information on the biology of Epinephelus lanceolatus is incomplete compared to that of its sister species, the Atlantic E. itajara (Randall 1967; Bullock et al. 1992; Sadovy and Eklund 1999). Both species are particularly vulnerable to fishing when they form large spawning aggregations (Coleman et al. 1996; Sadovy and Domeier 2005; Saenz-Arroyo et al. 2005). E. lanceolatus does not become sexually mature until it reaches $129 \mathrm{~cm}$ TL. It is highly valued in Asian fish markets (Randall and Heemstra 1991; Lee and Sadovy 1998; McGilvray and Chan 2003), resulting in special effort to catch it at islands of the western Pacific. Based on knowledge of fishermen and divers, local extinctions and extreme scarcity have been reported for Western Pacific localities (Lavides et al. 2009; Zgliczynski et al. 2013). The species is classified by the IUCN as "vulnerable", the second highest risk of extinction (Shuk Man and Chuen 2006).

Fishing pressure on this species has recently decreased in some areas as a result of protective legislation. It is illegal to spear this species in South Africa, where it is known as Brindle 


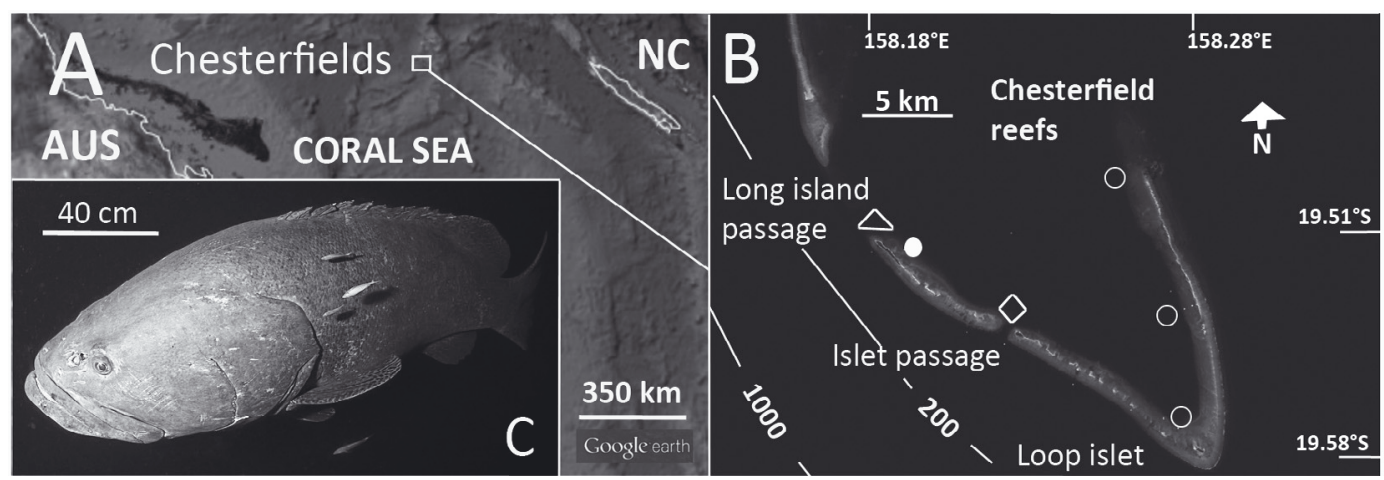

Fig. 1. A: The Chesterfield reefs in the Coral Sea situated midway between the east coast of Australia (AUS) and New Caledonia (NC). B: Close up on the study site that includes Long Island (North-West of the Chesterfield reefs), which is delineated by two passages. The plain white circle indicates the VR2W receiver called "Home" as it was standing in the vicinity of the Giant Grouper cave. The triangle indicates the VR2W called "LP" standing for "Large Pass", corresponding to the large passage North of Long Island. The diamond indicates the VR2W called "SP" standing for "Small Pass", corresponding to the Islets passage. These three receivers recorded detections from the tagged Giant Grouper and these same symbols were also used to describe spatial and temporal distributions of detections in Figure 2A. The three other receivers on the Eastern side of the Chesterfields reef lagoon are represented by empty circles; they did not record any detection from the giant grouper. C: Picture of the $1.95 \mathrm{~m}$ TL Epinephelus lanceolatus that was caught and released in good health near receiver Home.

Bass (van der Elst 1981), and in Australia, where it is called Queensland Grouper; such protection should be adopted elsewhere. The rearing of the species for human consumption has been successful (McGilvray and Chan 2003).

The capture of a large adult of Epinephelus lanceolatus during a program of acoustic tagging of adult tiger sharks in the Chesterfield Islands provided the opportunity to tag as well as document its movements.

\section{Materials and methods}

The Chesterfield Islands are a series of 11 islets, of which the largest is Long Island (length of $3.4 \mathrm{~km}$ ). Numerous reefs and channels, typically 30-40 m deep, lie on a north-south oceanic ridge in the Coral Sea, isolated from Australia to the west and New Caledonia to the east by app. $800 \mathrm{~km}$ in either direction (Fig. 1A). The islands are surrounded by deep drop-offs to over $1000 \mathrm{~m}$. The islets were named for the whaling ship Chesterfield that explored the Coral Sea in the 1790s. They were used for commercial whaling in the early 1860s, and guano was extracted in the 1870s. They have been uninhabited for over 40 years. Large-scale illegal fishing still takes place for sharks and reef fishes of high value, such as the Giant Grouper (Clua et al. 2011). Kulbicki et al. (1994) published a checklist of the fishes of the Chesterfield Islands. They reported 866 species, representing 34 families, noting closer affinity to the fish fauna of New Caledonia than to the Great Barrier Reef.

Acoustic telemetry was used for studying the movements of large sharks in the Chesterfield Islands. An acoustic array of six Vemco VR2W receivers were moored on concrete-filled tyres at depths of 5-25 m in August 2010 and maintained until January 2013 to track the movements of tagged Tiger Shark (Fig. 1B, see Werry et al. 2014). One receiver was moored on a patch reef in the lagoon opposite Long Island at a depth of approx. $5 \mathrm{~m}$. For the purpose of this study, it was named "Home". Another receiver was moored at the edge of the large passage north to Long Island, down the reef slope at $25 \mathrm{~m}$ depth and $1300 \mathrm{~m}$ from the receiver Home; this receiver was named LP for "Large Pass". A third receiver was moored $8250 \mathrm{~m}$ south of the receiver Home at a depth of $22 \mathrm{~m}$, at the entrance of a smaller passage; it was named SP for "Small Pass". The three other receivers were moored on the Eastern side of the lagoon and did not get any specific name during this study (see Fig. 1B). On August 16, 2010, while fishing for large sharks with a barbless hook and heavy line, a Giant Grouper $1.95 \mathrm{~m}$ TL was caught in close vicinity of receiver "Home" (Fig. 1B). The fish was restrained in a special harness in the sea that provided efficient protection and oxygenation of the animal, and avoided the use of anesthetic during tagging. A small incision was made on the central part of the abdomen, a transmitter (Vemco V16, $69 \mathrm{kHz}$, length $54 \mathrm{~mm}$, weight in the water $8.1 \mathrm{~g}$, battery life $>7$ years, delay pulse $90 \mathrm{~s}$ ) was inserted into the peritoneal cavity, and the incision was closed with stitches. The fish swam away vigorously on release (Fig. 1C).

Range tests were conducted to assess the distance from which the receivers were able to detect the tagged fish. These showed that detections significantly dropped after $400 \mathrm{~m}$.

In November 2011, the acoustic data were downloaded, batteries were replaced, and the receivers redeployed. The gear was completely retrieved in January 2013. Following the data download, we cleaned the raw data by deleting the rare false detections. The valid detections were then sorted by site, date, and time. For each receiver, we determined the number of detections and a residency index, defined as the number of days the fish was detected at a given receiver, divided by the total number of days at liberty since tagging.

We used a generalized linear modelling framework (GLM) to examine the effects of time of year (Month), time of day (Hour) and site (Receiver) factors on the presence of the grouper. The cyclicity of the "Month" and "Hour" factors were modelled by including the variables as the cyclical function of their sine and cosine components. The analysis used a binomial error structure with a logit link function. We coded the binomial dependent variable with 1 when the fish was detected 

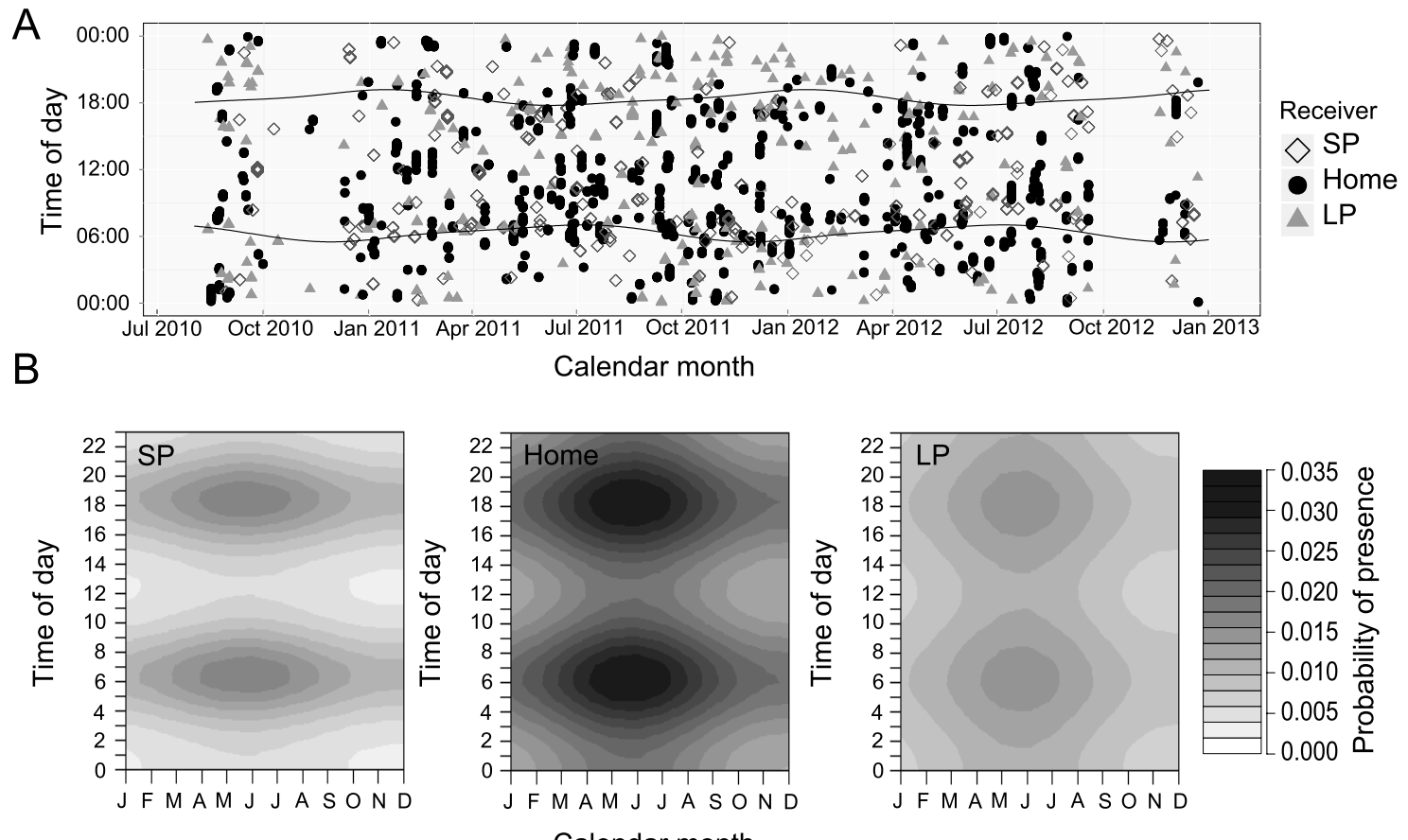

Calendar month

Fig. 2. A: Scatterplot of diel detection patterns of the Giant Grouper recorded at Chesterfield reefs between August 2010 and January 2013. Horizontal curves show daily sunrise and sunset. Shapes of the symbols on the scatterplot correspond to the receiver locations indicated in the map in Figure 1B. B: Predicted probability of presence of the grouper at the three receivers for each calendar month and time of day inferred from the most parsimonious GLM model.

and 0 when not detected for each hour of each day, and at each receiver. Therefore, the fish had a total of 72 records for each calendar day. Akaike's Information Criterion (AIC) was used to compare relative model support, where lower AIC values indicate greater support for the model.

We used network analysis to investigate the spatial dynamics of the grouper. We implemented an Empirical derived Markov chain (EDMC) analysis, which takes into account the frequency of movements between receivers but also the residency times and absence from the array (see Garcia et al. 2015; Stehfest et al. 2015). A Markov chain is a random process and consists of transitions from one state to another (in our case from receiver to receiver). The raw series of acoustic detections was organized into an hourly detection time series. For every hourly time step, if the fish was detected by a receiver, then the receiver ID was assigned to the state; if the fish was not detected, it was assigned an absent state. A movement count matrix was then computed containing movements between each receiver, as well as the movements from each state to itself (residency periods when the fish stayed at the same receiver) and movements to the absent state (transition periods outside of detection range). The transition probability matrix was constructed by dividing each number of transitions made from one state to another or itself by the number of transitions made from the state. We also calculated the eigenvector centrality of each receiver which is a measure not only of the centrality of a receiver, but also of the centrality of the receivers it is connected to (see Stehfest et al. 2015). The same analysis was reiterated using day of year instead of hour in order to test for differences in movement and residency timing.

\section{Results}

The Giant Grouper was monitored for a total of 857 days within the study area. It was detected on 135 days (15.75\%) at receiver LP, 196 days $(22.87 \%)$ at receiver Home and 161 days $(18.78 \%)$ at receiver SP, for a total of 385 days $(44.92 \%)$ on at least one receiver, 101 days $(11.78 \%)$ on a minimum of 2 receivers and 6 days $(0.70 \%)$ on the three receivers (Fig. 2A; Table 1). The best GLM model determined by the lowest AIC was one that incorporated the factors Month, Hour and Receiver and an interaction between Hour and Receiver (Model 9; Tables S.1 and S.2). For all receivers, the lowest probability of presence was in October and November and the greatest probability of presence outside these two months was in the morning between 6:00 and 8:00 AM (Fig. 2B). Based on real detections, the fish was totally absent from the area during October and November 2010 and 2012, but still present during the same months in 2011 (Fig. 2A). Although the fish was more present at receiver Home compared to the others, the patterns of probabilities were consistent across all receivers (Fig. 2B) as the fish was detected by all receivers similarly throughout the monitoring period (Fig. 2A).

Transition probabilities between states revealed low residency at the daily scale (Fig. 3A) and relatively high residency at the hourly scale (Fig. 3B) with the highest probability of hourly residency being at receiver Home. Movements between receivers occurred mostly at a daily scale (Fig. 3A) rather than at an hourly scale (Fig. 3B). Most movements occurred between receivers Home and LP but some direct movements in both directions did also occur between the receivers LP and SP, 
Table 1. Receiver statistics. The residency index and number of detections are given by receiver as well as for all receivers combined. Residency index is defined as the number of days the fish was detected divided by the number of monitoring days. The eigenvector centrality values of the matrices of movement between receivers are given for the daily and hourly time scales.

\begin{tabular}{lcccc}
\hline Receiver & $\begin{array}{c}\text { Residency } \\
\text { index }\end{array}$ & $\begin{array}{c}\text { Number of } \\
\text { detections }\end{array}$ & $\begin{array}{c}\text { Eigenvector centrality } \\
\text { (Day) }\end{array}$ & $\begin{array}{c}\text { Eigenvector centrality } \\
\text { (Hour) }\end{array}$ \\
\hline SP & 0.157 & 678 & 0.099 & 0.008 \\
Home & 0.228 & 3587 & 0.145 & 0.020 \\
LP & 0.187 & 1098 & 0.118 & 0.010 \\
All & 0.449 & 5363 & & \\
\hline
\end{tabular}

\section{A. Daily scale}
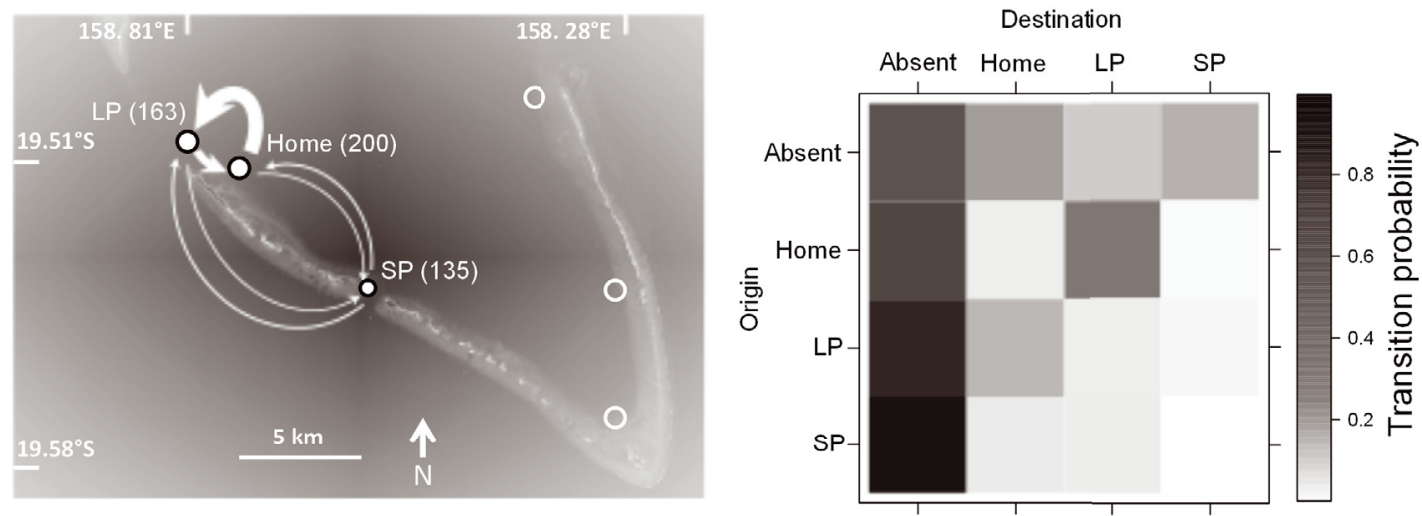

\section{B. Hourly scale}
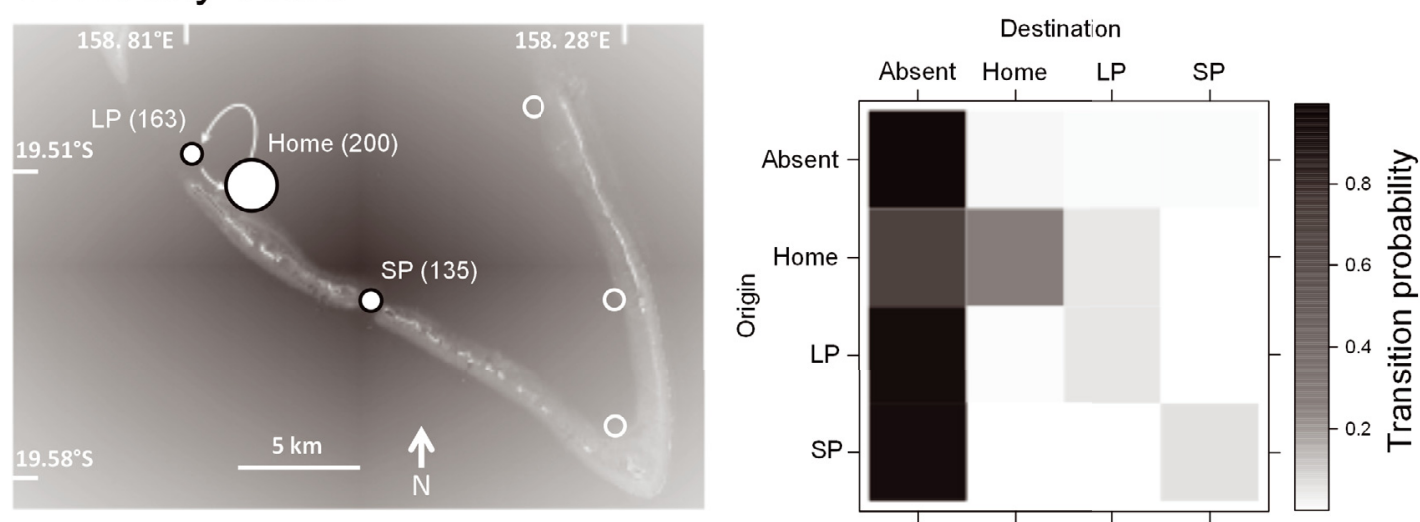

Fig. 3. Movement and residency of the grouper over two temporal scales: using A- daily and B- hourly time series of detections. For each case, a map showing the movements is presented in which arrow size is proportional to the transition probabilities between receivers and filled circles are proportional to the probability of residency. Number of day the fish was detected at each receiver is indicated in parentheses. Empty circles represent the three other receivers located on the east side which did not record any detections.

probably along the outer slope of the barrier reef (Fig. 3A). The receiver Home was the most central as suggested by the highest eigenvector centrality (Table 1). Probabilities of being in an absent state or coming from/going to an absent state were higher at the hourly scale (Fig. 3). The fish was never recorded by the three other receivers on the opposite side of the lagoon (Fig. 3)

\section{Discussion}

Movements occurred between the three receivers in the lagoon and channels surrounding Long Island, but the distribution of detections suggests that the usual shelter of this grouper would be around receiver Home, as confirmed by the sighting during a diving session of a Giant Grouper of a similar size in a reef cave of the area in August 2010 (J.C. Toison, Pers. Comm.). The fish used the adjacent passages (in particular the closest Long Island passage) mainly at dawn (between 5:00 and 12:00 AM), probably for foraging purposes. The lower detection rate recorded outside the morning period (Fig. 2B) may be due to the fish residing in a cave, which would reduce its detection by the receivers. High probabilities of being out-of-receiver range are common in reef fish (Garcia et al. 2015) which may be due to the distance between receivers or 
to the sheltering behaviour of the studied species. Analysis of the movement sequences also showed that the grouper went from one passage to another by swimming either inside the lagoon or along the outer slope. The second hypothesis seems more plausible as the way inside the lagoon preventing any detection by the receiver Home would oblige the grouper to swim and remain on a nearly bare sandy bottom area, which is probably less attractive than the outer slope of the barrier reef that hosts more potential prey. The differences between movement matrices at hourly and daily scales (Fig. 3) indicate that movements between receivers took more than one hour. The absence of any detections on the three other receivers located inside the Chesterfield lagoon indicated a strong attachment to the passages and outer slope, with a strong residency pattern (44.9\% of days) in an area of about $12 \mathrm{~km}$ of diameter delineated on the North and South sides by the two reef passages.

Based on the definition provided by Colin et al. (2003), spawning aggregations of E. lanceolatus were observed along the west coast of New Caledonia in October and November (C. Chauvet, Pers. Comm.). The absence of the tagged E. lanceolatus in the Chesterfields during this period and could be explained by migration for spawning. Our observations of E. lanceolatus in the Chesterfields are also consistent with a 2-month period which is dedicated to mating by its sister species, E. itajara, in the Caribbean Sea (Mann et al. 2009).

The detection of the tagged grouper in the network of receivers during the mating period in 2011 could be explained by its failure to build up the caloric reserve needed for the long migration in the open sea to the spawning site. "Skipped spawning" has been documented for several fish species (Rideout and Tomkiewicz 2011).

A slight increase in activity, mainly at dusk, was noted for the months May to August prior to the migration before the end of September (see Fig. 2B), indicating an increase in foraging needed for the production of gametes and the upcoming intense activity of spawning (Rideout and Tomkiewicz 2011). Regarding the observed site fidelity of the tagged E. lanceolatus, Elkund and Schull (2001) showed that among the 50 tagged Goliath Grouper (E. itajara) that were resighted in the framework of their study, 64\% had been tagged inshore (outside the spawning season) and resighted on the same site within two weeks to two months post-tagging. They could then show evidence of site fidelity, already mentioned by Sadovy and Elkund (1999). One fish tagged at a popular diving site was resighted on the same wreck repeatedly for eight months. Our findings on E. lanceolatus are consistent with such site fidelity, except for the spawning season.

\section{Conclusion}

Our data suggest that Epinephelus lanceolatus moves beyond its Chesterfield Islands home area only for spawning. As a large apex predator, the population of E. lanceolatus at any site within its broad distribution is very low, even without fishing. Because of its enormous size, it is the goal of fishermen, whether by hook and line or spear, to land one of these huge fish. Its high value in the live reef fish trade (McGilvray and Chan 2003), makes it very susceptible to targeted fishing, especially if spawning sites are discovered. This results in the removal of a higher percentage of the males of the population and increases the danger of extinction. The low population of the species, its high value, and its vulnerability should be taken into account for conservation and management strategies. Artisanal fishing does occur in the Chesterfield Islands. It primarily targets invertebrates (such as sea cucumbers and lobsters) but it also includes reef fishes (Clua et al. 2011). The data provided by our study will help to define the Essential Fish Habitat (see Conover et al. 2000) of this endangered species and will aid in creating a Marine Protected Area (MPA) for the Chesterfield Islands. The optimal MPA would be one that includes the entire critical habitat for the species, including one or more spawning sites. Further acoustic tagging, especially if based on satellite tracking methodologies, is needed to identify and protect the spawning sites.

Acknowledgements. We acknowledge the financial support of the Agence Française de Développement through the funding of the CRISP programme and the technical support of the Secretariat of the Pacific Community in Noumea. We thank Thomas Vignaud for the photo of the tagged E. lanceolatus. We also thank the IRD team in Nouméa, in particular Armelle Renaud, for the technical support for retrieving the VR2 receivers from the study area in January 2013. This work was conducted under permit No. 6024-4916/DENV/SMer (New Caledonia) and ethics ENV/17/09/AEC (Griffith University). The contribution of two anonymous reviewers and the associate editor were highly appreciated for the improvement of this paper.

\section{References}

Bullock L.H., Murphy M.D., Godcharles M.F., Mitchell M.E., 1992, Age, growth, and reproduction of jewfish Epinephelus itajara in the eastern Gulf of Mexico. Fish. Bull. 90, 243-249.

Clua E., Gardes L., McKenna S., Vieux C. (eds.), 2011, Contribution to the biological inventory and resource assessment of the Chesterfield reefs. - Apia, Samoa: SPREP. 264 p.

Coleman C.F., Koenig C.C., Collins A.L., 1996, Reproductive styles of shallow-water groupers (Pisces: Serranidae) in the eastern Gulf of Mexico and the consequences of fishing spawning. Environ. Biol. Fish. 47, 129-141.

Colin P.L., Sadovy Y.J., Domeier M.L., 2003, Manual for the Study and Conservation of Reef Fish Spawning Aggregations. Society for the Conservation of Reef Fish Aggregations Special Publication No. 1 (Version 1.0), pp. 1-98+iii.

Conover D.O., Travis J., Coleman F.C., 2000, Essential fish habitat and marine reserves: An introduction to the second mote symposium in fisheries ecology. Bull. Mar. Sci. 66, 527-534.

Domeier M.L., Colin P.L., 1997, Tropical reef fish spawning aggregations: defined and reviewed. Bull. Mar. Sci. 60, 698-726.

Domeier M.L., Colin P.L., Donaldson T.J., Heyman W.D., Pet J.S. et al., 2002, Transforming coral reef conservation: reef fish spawning aggregations component. Spawning Aggregation Working Group Report, The Nature Conservancy, Hawaii, 85 p.

Eklund A.M., McClellan D.B., Harper D.E., 2000, Black grouper aggregations in relation to protected areas within the Florida Keys National Marine Sanctuary. Bull. Mar. Sci. 66, 721-728.

Eklund A.M., Schull J., 2001, A stepwise approach to investigating the movement patterns and habitat utilization of goliath grouper, Epinephelus itajara, using conventional tagging, acoustic telemetry and satellite tracking. In Electronic Tagging and Tracking in Marine Fisheries (pp. 189-216). Springer Netherlands. 
Garcia J., Mourier J., Lenfant P., 2015, Spatial behavior of two coral reef fishes within a Caribbean Marine Protected Area. Mar. Envir. Res. 109, 41-51.

Grant E.M., 1982, Guide to Fishes. 5th edition Dept. of Harbours and Marine, Brisbane, 896 p.

Heemstra P.C., Randall J.E., 1993, FAO species catalogue. Vol. 16. Groupers of the world (Family Serranidae, Subfamily Epinephelinae). An annotated and illustrated catalogue of the grouper, rockcod, hind, coral grouper and lyretail species known to date. FAO Fisheries Synopsis. No. 125, Vol. 16. Rome, FAO. $421 \mathrm{p}$.

Kulbicki M., Randall J.E., Rivaton J., 1994, Checklist of the fishes of the Chesterfield Islands (Coral Sea). Micronesica 27, 1-43.

Lavides M.N., Polunin, N.V., Stead S.M., Tabaranza D.G., Comeros M.T., Dongallo J.R., 2009, Finfish disappearances around Bohol, Philippines inferred from traditional ecological knowledge. Environ. Conserv. 36, 235-244.

Lee C., Sadovy Y., 1998, A taste for live fish: Hong Kong's Live Reef Fish Market. Naga (The ICLARM Quarterly) April-June, 1998, 38-42.

McGilvray F., Chan T., 2003, Market and industry demand issues in the live reef fish food trade. SPC Live Reef Fish Information 36, 36-39.

Mann D.A., Locascio J.V., Coleman F.C., Koenig C.C., 2009, Goliath grouper Epinephelus itajara sound production and movement patterns on aggregation sites. Endang. Species Res. 7, 229-236.

Randall J.E., 1967, Food habits of reef fishes of the West Indies. Studies in Tropical Oceanography 5, 665-847.

Randall J.E., 1999, Report on the fish collections of the Pitcairn Islands. Atoll Research Bulletin 461, 1-36.

Randall J.E., Heemstra P.C., 1991, Revision of the Indo-Pacific groupers: (Perciformes: Serranidae: Epinephelinae): with descriptions of five new species. Indo-Pacific Fishes 20: 1-332.

Rideout R.M., Tomkiewicz J., 2011, Skipped spawning in fishes: more common than you might think. Marine and Coastal Fisheries 3, 176-189.
Sadovy Y., Eklund A.M. 1999 Synopsis of biological data on the Nassau grouper, Epinephelus striatus (Bloch, 1792), and the jewfish, E. itajara (Lichenstein, 1822).

Sadovy Y., Domeier M., 2005, Are aggregation-fisheries sustainable? Reef fish fisheries as a case study. Coral Reefs 24, 254-262.

Sáenz-Arroyo A., Roberts C.M., Torre J., 2005, Using fishers' anecdotes, naturalists' observations and grey literature to reassess marine species at risk: the case of the Gulf grouper in the Gulf of California, Mexico. Fish Fish. 6, 121-133.

Sale P., 2004, Connectivity, Recruitment Variation, and the Structure of Reef Fish Communities. Integr. Comp. Biol. 44, 390-399.

Shuk Man C., Chuen N.W., 2006, (Grouper \& Wrasse Specialist Group) Epinephelus lanceolatus. The IUCN Red List of Threatened Species. Version 2015.2. <www.iucnredlist.org>. Downloaded on 28 July 2015.

Stehfest K.M., Patterson T.A., Barnett A., Semmens J.M., 2015, Markov models and network analysis reveal sex-specific differences in the space-use of a coastal apex predator. Oikos. http:// dx.doi.org/10.1111/oik.01429.

Van der Elst R., 1981, A Guide to the Common Sea Fishes of Southern Africa. C. Struik, Cape Town, 367 p.

Werry J.M., Planes S., Berumen M.L., Lee K.A., Braun C.D., Clua E., 2014, Reef-Fidelity and Migration of Tiger Sharks, Galeocerdo cuvier, across the Coral Sea. PLos One 9, e83249.

Witzell W.N., 1981, Predation on Juvenile Green Sea Turtles, Chelonia Mydas, by a Grouper, Promicrops Lanceolatus (Pisces; Serranidae) in the Kingdom of Tonga, South Pacific. Bull. Mar. Sci. 31, 935-936.

Zgliczynski B.J., Williams I.D., Schroeder R.E., Nadon M.O., Richards B.L., Sandin S.A., 2013, The IUCN Red List of Threatened Species: an assessment of coral reef fishes in the US Pacific Islands. Coral Reefs 32, 637-650. 